\title{
Quality analysis of different marketed brands of paracetamol available in Bangladesh
}

\author{
Auditi Kar1 ${ }^{1}$ Mohammad Nurul Amin², *Mohammad Salim Hossain¹, Md. Emdadul Hasan Mukul ${ }^{3}$, \\ Md. Saif Uddin Rashed ${ }^{4}$ and Md. Ibrahim ${ }^{2}$ \\ ${ }^{1}$ Department of Pharmacy, Noakhali Science and Technology University, Noakhali-3814, Bangladesh \\ ${ }^{2}$ Department of Pharmacy, Atish Dipankar University of Science and Technology, Banani, Dhaka-1213, Bangladesh \\ ${ }^{3}$ Department of Pharmacy, Khwaja Yunus Ali University, Sirajganj-6751, Bangladesh \\ ${ }^{4}$ Department of Statistics, Jahangir Nagar University, Savar-1342, Bangladesh
}

\begin{abstract}
Paracetamol is a widely used analgesic and antipyretic drug worldwide. The present study was conducted to analyze the quality of seven marketed brands of paracetamol tablet formulation manufactured by different multinational and national companies. The tablet formulations of different brands were tested for various parameters like weight variation, hardness, friability, disintegration time and dissolution profile using standard techniques to evaluate their quality. The values were compared with the standards. Weight variation value requirement was complied by all brands. All studied samples except two local products complied with the standard specification for tablet hardness. All brands showed impressive friability values and products of multinational companies comparatively exhibited the highest values. Disintegration time for all brands was within 15 minutes also complying the USP (United State of Pharmacopeia) recommendation. Moreover, the release rate of different brands of paracetamol was satisfactory within 45 minutes and ranged from $79.82 \%$ to $103.53 \%$. Therefore, it can be concluded that almost all the brands of paracetamol that are available in Bangladesh meet the USP specification for quality control analysis.
\end{abstract}

Key Words: Paracetamol, hardness, friability, disintegration, dissolution.

\section{INTRODUCTION}

We are consuming several drugs as medicines in our daily life unknowing their nature, toxicity and mechanism of action on the body. Paracetamol or acetaminophen is one of them which we generally use to treat headache, fever and certain pains. N-acetyl-para-aminophenol is the chemical name of this drug (Vidhya and Bai, 2012; Jóźwiak-Bebenista and Nowak, 2014). Paracetamol is commonly used for its antipyretic and analgesic activities (Chun et al., 2009). It is used for treating certain mild-tomoderate pain, including that caused by flu, sprains, cold, headaches, dysmenorrhea, toothaches and minor arthritis pain etc. (Bertolini et al., 2006). Probably, it exerts consequent effect through the cyclooxygenase (COX) pathway. Nonsteroidal anti-inflammatory drugs (NSAIDs) act through this pathway by inhibiting the synthesis of prostaglandins (PGs) (Anderson, 2008). Generally, paracetamol is assumed to be a weak suppressor of the production of PGs. It also reduces PG concentrations in vivo (Graham and Scott, 2005). Paracetamol is safe at appropriate dosage. Actually, appropriate dosage of any drug shows no serious adverse or side effects. However, overdoses or prolonged duration of taking any drug may exhibit side effects, especially in the liver (Bertolini et al., 2006; Graham et al., 2005). Paracetamol overdose may cause serious complications in human body. It has been reported that amounts of $150 \mathrm{mg}$ in a child and $7.5 \mathrm{~g} / \mathrm{kg}$ in an adult are the lowest acute doses of paracetamol capable of exhibiting toxicity (Bertolini et al.,
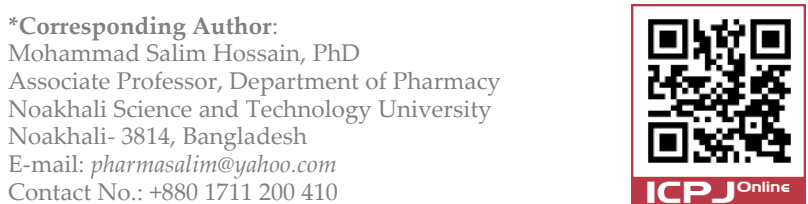

2006). Typically, liver is the most involved organ in paracetamol acute toxicity. Paracetamol is extensively metabolized by the liver and approximately $90 \%$ is eliminated in the urine mainly as sulphate and glucuronide conjugates. A small fraction $(<5 \%)$ of paracetamol is excreted as unchanged form (Bertolini et al., 2006; Vidhya and Bai, 2012). Hepatotoxicity due to paracetamol overdose leads to liver injury and is also a common cause of poisoning worldwide. Increased paracetamol toxicity may develop hepatic encephalopathy. Moreover, large doses of this drug also promote the risk of upper gastrointestinal complications like stomach bleeding (Vidhya and Bai, 2012). Kidney is the second target organ of paracetamol toxicity (Bertolini et al., 2006). It has been revealed that heavy use of paracetamol (average amount of 300 grams per year or $1 \mathrm{~g}$ per day) leads to a condition known as 'Small Indented and Calcified Kidneys' (SICK) (Beasley et al., 2008). Hence, renal impairment occurs after acute paracetamol overdose. Furthermore, renal dysfunction may occur with significant hepatotoxicity or without hepatotoxicity. Renal impairment is more common after sustained repeated excessive dosing (Bertolini et al., 2006; Prescott et al., 1982; Campbell and Baylis, 1992; Davenport and Finn, 1988). There is a dose-dependent relationship between chronic use of paracetamol and an enhanced risk of end-stage renal disease, as demonstrated by a casecontrol study involving 1,077 individuals (Perneger et al., 1994). Injury to other organ is extremely rare. Pancreatic toxicity is rarely reported (Gilmore and Tourvas, 1977; Mofenson et al., 1991). Additionally, paracetamol interferes with DNA synthesis and promotes genotoxicity and carcinogenicity (Télez et al., 2000; Abreu and MoraesSantos, 2011).

As paracetamol is a popular and widely used overthe-counter analgesic (pain reliever) and antipyretic (fever reducer), consciousness among the people is essential to 
avoid the complications mentioned above. In Bangladesh, there are a good numbers of certified manufacturers involved in paracetamol tablet preparation which includes both Bangladeshi and multinational companies. A common truth is, not all the manufacturers are equally accepted to the consumers. In a general sense most of the consumers choose the popular brands of medicines though they are not really concerned about the potency and overall quality of the drugs. In this study, 7 brands of paracetamol were selected from different popular pharmaceutical industries. The vital purpose of this study was to analyze the quality of the marketed paracetamol tablets by performing weight variation, hardness, friability, disintegration and dissolution test. We analyzed seven popular brands of paracetamol namely Servigesic (Novertis Bd Ltd.), Xpa (Aristopharma Ltd), Renova (Opsonin Pharma Ltd.), Napa (Beximco Pharmaceuticals Ltd.), Reset (Incepta Pharmaceuticals Ltd.), Ace (Square Pharmaceuticals Ltd.), Parapyrol (GlaxoSmithKline Pharmaceuticals Ltd.). Consciousness among the general consumers is expected to grow with this kind of study and this experimental evaluation will lead them to choose the quality product among thousands present product in the market.

\section{MATERIALS AND METHODS}

Instruments: Analytical balance, UV- Spectrophotometer, Tablet hardness tester, Dissolution test apparatus, Disintegration test apparatus, Friability test apparatus.

Reagents: Standard Paracetamol, Sodium Hydroxide $(\mathrm{NaOH})$, Potassium Dihydrogen Phosphate $\left(\mathrm{KH}_{2} \mathrm{PO}_{4}\right)$.

Collection of sample: Seven variably popular brands of Paracetamol were collected from the local retail markets (Sonapur, Noakhali). About 25 tablets of each brand were collected for the analysis. The information of samples were properly checked such as name of the manufacturer, batch number, and date of manufacturing, date of expiry, manufacturing license number and DAR number at the time of purchase. In this study, we used code number (given by us) for each brand of paracetamol tablet formulation (table 1). Moreover, in discussion part, we have identified national and multination companies in each figure by using color for multinational products.

Weight variation test: This test has done to know content uniformity of each tablet, whether the tablets were in same shape, size and thickness. Fourteen tablets were selected from each of the brand and weighed individually using an analytical balance. The average weight of the tablets was calculated. Then $\%$ of weight variation is calculated by using the following formula:

$\%$ of weight variation $=\frac{\text { Average weight }- \text { Individual weight }}{\text { Average weight }} \times 100$

Hardness test: Tablet hardness is defined as the load required, crushing a tablet. Sometimes it is also termed as tablet crushing strength. In this study Monsanto Hardness Tester was used.

Disintegration test: Disintegration time is the length of time required for causing disintegration of tablet. Disintegration is the break down process of tablet into smaller particles and is the first step towards dissolution. USP
Table 1: Code numbers of seven brands paracetamol tablet formulation.

\begin{tabular}{cc}
\hline Code Number & Company Type \\
\hline PARA-1 & Multinational \\
PARA-2 & Local/National \\
PARA-3 & Local/National \\
PARA-4 & Local/National \\
PARA-5 & Local/National \\
PARA-6 & Local/National \\
PARA-7 & Multinational \\
\hline
\end{tabular}

disintegration apparatus containing six glass tubes was used for the purpose.

To test for disintegration time, one tablet is placed in each tube and the basket rack is positioned in a 1L beaker containing $0.1 \mathrm{~N} \mathrm{HCl}$ acid solution at $37 \pm 2^{\circ} \mathrm{C}$ temperature. A standard motor driven device is applied to move the basket assembly containing tablets up and down at a frequency of 28 to 32 cycles per min. The disintegration time of each paracetamol tablet was determined and also the average disintegration time of each brand was calculated (Ahmed et al., 2003).

Friability test: The friability test is closely related to tablet hardness. It is usually measured by the use of the Roche Friabilator.

A number of 10 tablets were initially weighed and placed into friabilator. The friabilator was operated at 25 rpm. After four minutes or 100 revolutions, the tablets were weighed again and the percent (\%) friability was then calculated by using following formula (Kalakuntla et al., 2010; Karmakar and Kibria, 2012). Generally the acceptable range of weight loss of a tablet is less than 0.5 to $1 \%$ (Karmakar and Kibria, 2012). If any tablet shows capping, laminating or breaking, the loss is not to count as it is considered as failed the requirement.

$\%$ Friability $=\frac{\text { Weight before test }- \text { Weight after test }}{\text { Weight before test }} \times 100$

Dissolution test: Dissolution is the property or tendency of a drug to undergo solution, which affects the rate of drug absorption. Generally dissolution test is performed by using Dissolution Tester-USP to determine drug release

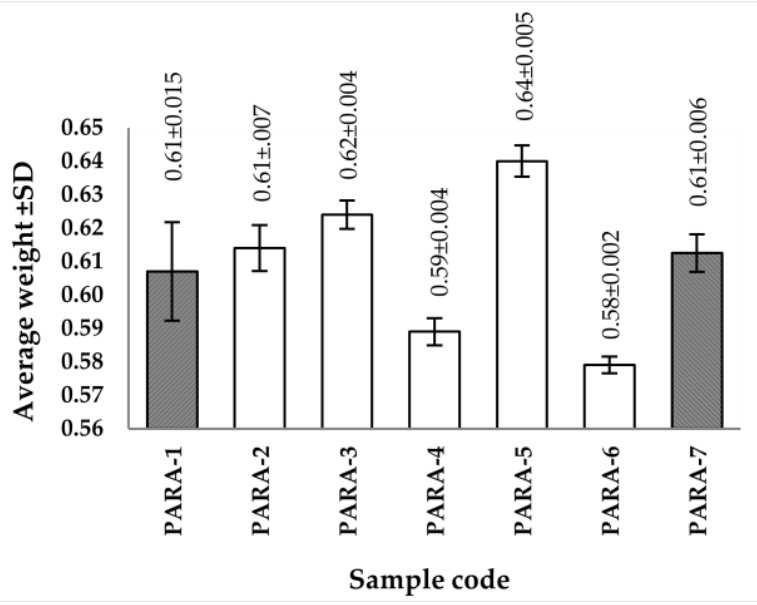

Figure 1: Weight variation of different brands of Paracetamol. 


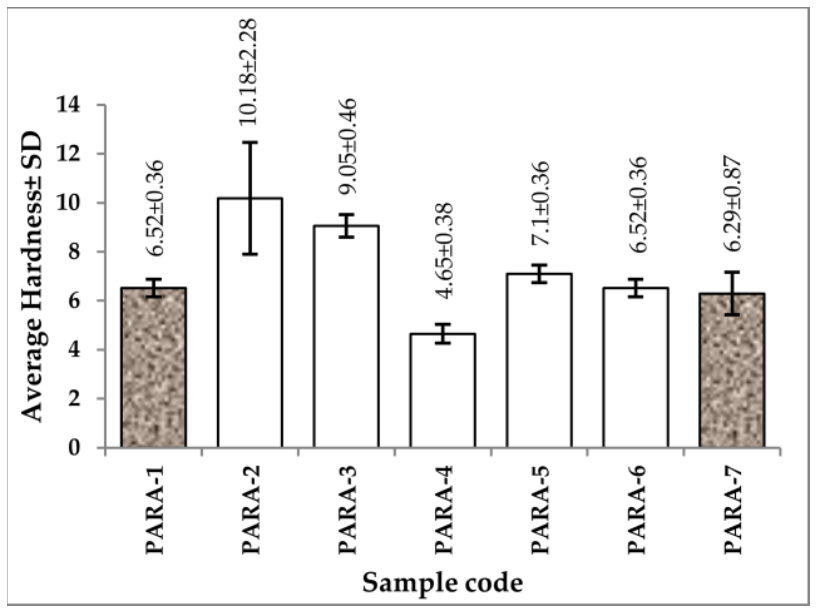

Figure 2: Hardness of different brands of Paracetamol.

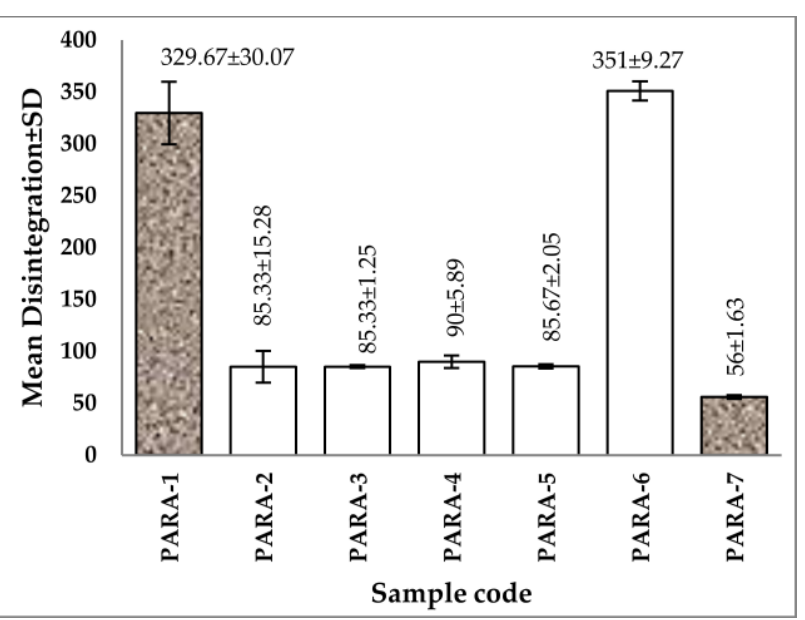

Figure 4: Disintegration time of different brands of Paracetamol tablet.

pattern during a specific period of time (Kishore et al., 2011). $900 \mathrm{ml}$ of phosphate buffer, $\mathrm{pH} 7.4$ was used as dissolution medium (Kishore et al., 2011).

In general, a single tablet is placed in a basket fastened to the bottom of the shaft connected to a variable speed motor. The dissolution medium was heated up to $37 \pm 0.5^{\circ} \mathrm{C}$ by an auto heater. One tablet was put into the basket and stirred immediately at 75 revolutions per minute (rpm). The amount of dissolved Paracetamol was determined from UV absorbance at the wavelength of maximum absorbance at about $257 \mathrm{~nm}$ in comparison with a standard Paracetamol solution in the same medium. By measuring the absorbance, the percentage (\%) of drug release was calculated (Kishore et al., 2011; Kalakuntla et al., 2010).

\section{RESULTS AND DISCUSSION}

Weight variation: The weights of different brands of Paracetamol tablets were determined with the help of an electronic balance. Tablet weights should be controlled within a tight range. This will contribute to better tablet hardness and friability. According to British Pharmacopoeia, the acceptable limit for the deviation of weight for tablets having average weight of $250 \mathrm{mg}$ or more should not exceed 5\% (Karmakar and Kibria, 2012).

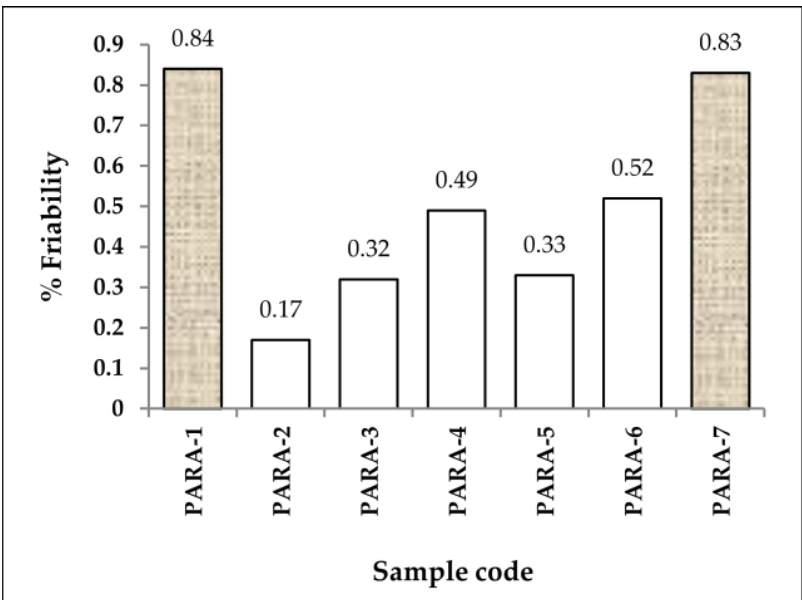

Figure 3: \% Friability of various brands of Paracetamol tablet.

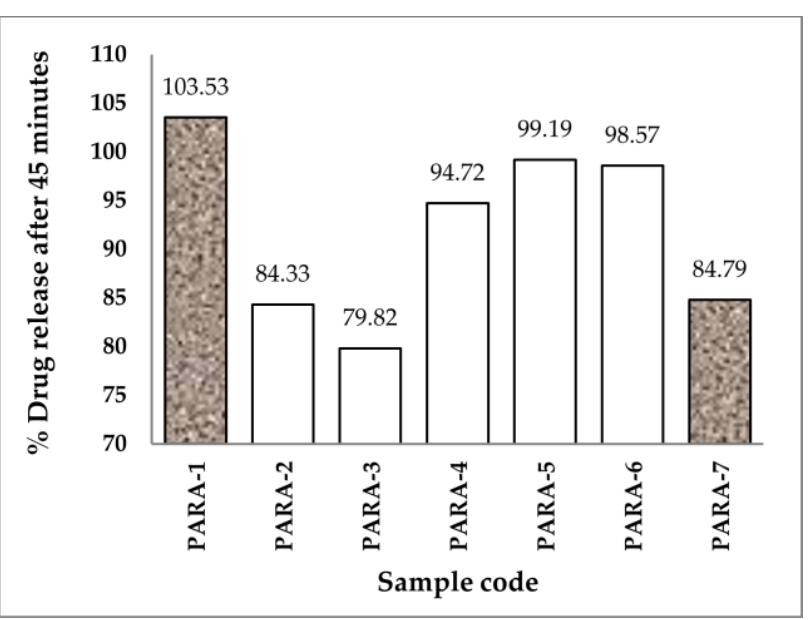

Figure 5: Dissolution (\% drug release) of different brands of Paracetamol after 45 minutes.

It is observed from this study that almost all the samples meet the standard specification (figure 1). PARA5 shows comparatively higher value whereas PARA-6 exhibits comparatively lower value. PARA-1 and PARA-7 are the products of multinational companies namely Novertis and Glaxosmithkline, respectively (Habiband Alam, 2011). They showed comparatively same values.

Hardness: Hardness is the second most important physical feature for assessing tablet. It indicates the capability of a tablet to withstand mechanical shocks during handling in manufacturing, packaging and shipping (Karmakar and Kibria, 2012). In this study, hardness of different brands of paracetamol was measured by a digital hardness tester. The acceptable limit of hardness of a tablet is 4 to $7 \mathrm{kgf}$ (kilogram of force) (Ahmed et al., 2003; Musa et al., 2011). Besides, a force between $4-10 \mathrm{Kg}$ is also considered to be satisfactory, as reported by Bendari et al. (2015).

PARA-2 was the hardest of all the samples with a hardness of $10.18 \pm 2.28 \mathrm{kgf}$, indicating that it was much above the limit range of between 4 to $7 \mathrm{kgf}$ stated. PARA3 was also beyond the limit range $(9.05 \pm 0.46)$. Besides, remaining samples including multinational products complied with specification for tablet hardness (figure 2). 
Friability: The result of friability test as shown in figure 3 shows that all brands of tablet samples tested showed impressive friability values ranging from $0.17 \% \mathrm{w} / \mathrm{w}$ to $0.84 \% \mathrm{w} / \mathrm{w}$. This range of friability ensures that all the tablets of each brand were mechanically stable (Kalakuntla et al., 2010). Two multinational products (PARA-1 and PARA-7) showed comparatively higher \% weight loss of 0.84 and 0.83 accordingly whereas PARA-2 exhibited the lowest \% friability of 0.17 .

Disintegration: The disintegration time of all brands of paracetamol was satisfactory and ranged from $56 \pm 1.63$ seconds to $351 \pm 9.27$ seconds (figure 4 ), indicating that all the disintegration rates were within the official limits of 30 minutes (Musa et al., 2011). PARA-6 exhibited the highest disintegration time whereas PARA-7 showed the lowest value. Moreover, figure 4 also shows the disintegration time of various national and multinational pharmaceutical companies. It is seen from the results (figure 4) that none of the samples exceeded the specification for disintegration time. Therefore, it can be said that all the studied samples complied with the BP/ USP specification for tablet disintegration time.

Dissolution: Dissolution is an important quality control parameter. It is directly related to the absorption and bioavailability of a drug (Pabla et al., 2009). The present study found that at different time intervals drug release rate was better in various brands of paracetamol tablet.

After 45 minutes, the release rate of different brands of paracetamol was satisfactory and ranged from $79.82 \%$ to $103.53 \%$ (figure 5). The multinational product, PARA-1 showed the highest percentage of drug release of all the samples and the value was $103.53 \%$. Another multinational product, PARA-7 showed $84.79 \%$ drug release after 45 minutes. On the other hand, PARA-3 exhibited the smallest percentage of drug release $(79.82 \%)$ of all the brands of paracetamol. Furthermore, few national products such as PARA-4, PARA-5and PARA-6 showed moderate percentage of drug release and the values were $94.72 \%, 99.19 \%$ and $98.57 \%$ respectively.

\section{CONCLUSION}

Paracetamol is a widely used and well established antipyretic and analgesic drug. It is available in different brands in the current pharma market of Bangladesh. It occupies a unique position among analgesic drugs. Hence, it is one of the popular medicines throughout the world and probably the most commonly prescribed drug in children (Bertolini et al., 2006). However, paracetamol overdose may cause irreversible damage to the organism. Therefore, it is very important to the patient to be warned by pharmacists or doctors about the risk associated with the overuse of this drug.

The qualitative differences in seven brands of the paracetamol formulation were assessed by this study. The values were compared with the standards. This study showed that almost all brands of paracetamol meet the USP specification of different parameters. All studied samples complied with the USP specification, especially specification for tablet disintegration time, tablet friability and tablet dissolution. Multinational products showed the highest friability values. Moreover, in weight variation test, all brands complied with the standard specification. However, in the results of few parameters, a little deviation from standard was observed in the local brand of paracetamol when compared to those manufactured by the multinational companies. For example, all samples except two national products named PARA-2 and PARA3 complied with the specification for tablet hardness. Therefore, it is evident from the study that most of the brands tested showed good results. The proper authority needs to take further necessary steps to ensure the continuity in establishment of the product quality.

\section{REFERENCES}

Abreu, R.V., Moraes-Santos, T., (2011). The Protective Effect of coffe against paracetamol-induced hepatic injury in rats. Journal of Food Biochemistry, 35(6), 1653-1659. [DOI]

Ahmed, F., Das, A.K., Karmakar, U.K., Khaleque, T. Shill, M.C., (2003). Quality of Marketed Metronidazole Preparations in Bangladesh- An Analytical Overview. Journal of Biological Sciences, 3(10), 940-950. [DOI]

Anderson, B.J., (2008). Paracetamol (Acetaminophen): mechanisms of action. Paediatr Anaesth. 18(10), 915-921. [DOI]

Beasley, R., Clayton, T., Crane, J., von Mutius, E., Lai, C.K., Montefort, S., Stewart, A., ISAAC Phase Three Study Group. (2008). Association between paracetamol use in infancy and childhood, and risk of asthma, rhinoconjunctivitis, and eczema in children aged 6-7 years: analysis from Phase Three of the ISAAC programme. Lancet, 20, 1039-1048. [DOI]

Bendari, A., Al-Shehi, B., Ahuja, A., (2015). Comparison of Pharmaceutical Properties of Different Marketed Brands of Metronidazole Tablets available in Oman. International Journal of Pharmaceutical Archive, 4(2), 9-21.

Bertolini, A., Ferrari, A., Ottani, A., Guerzoni, S., Tacchi, R., Leone, S., (2006). Paracetamol: new vistas of an old drug. CNS Drug Rev, 12(3-4), 250-275. [DOI]

Campbell, N.R., Baylis, B., (1992). Renal impairment associated with an acute paracetamol overdose in the absence of hepatotoxicity. Postgrad Med J, 68(796) 116-118. [DOI]

Chun, L.J., Tong, M.J., Busuttil, R.W., Hiatt, J.R., (2009). Acetaminophen hepatotoxicity and acute liver failure. J Clin Gastroenterol, 43(4), 342-349. [DOI]

Davenport, A., Finn, R., (1988). Paracetamol (acetaminophen) poisoning resulting in acute renal failure without hepatic coma. Nephron, 50(1), 55-56. [DOI]

Gilmore, I.T., Tourvas, E., (1977). Paracetamol induced acute pancreatitis. Br Med J, 1(6063), 753-754. [DOI]

Graham, G.G., Scott, K.F., (2005). Mechanism of action of Paracetamol. Am J Ther. 12(1), 46-55. [DOI]

Graham, G.G., Scott, K.F., Day, R.O., (2005). Tolerability of Paracetamol. Drug Saf, 28(3), 227-240. [DOI]

Habib, A.M., Alam, M.Z., (2011). Business Analysis of Pharmaceutical Firms in Bangladesh: Problems and Prospects. Journal of Business and Technology (Dhaka), VI(01), 61-77.

Jóźwiak-Bebenista, M., Nowak, J.Z., (2014). Paracetamol: mechanism of action applications and safety concern. Acta Pol Pharm, 71(1), 11-23.

Kalakuntla, R., Veerlapati, U., Chepuri, M., Raparla, R., (2010). Effect of various super disintegrants on hardness, disinte-gration and dissolution of drug from dosage form. J. Adv. Sci. Res, 1(1), 15-19.

Karmakar, P., Kibria, M.G., (2012). In-vitro comparative evaluation of quality control parameters between Paracetamol and Paracetamol/caffeine tablets available in Bangladesh. Int. curr. pharm. J, 1(5), 103-109. [DOI]

Kishore, B.H., Venkareswararao, T., Sankar, K.R., Rao, B.S., (2011). Studies on dissolution rate of paracetamol tablets by using different polymers. J Glob Trends Pharm Sci, 2(1), 1-10.

Mofenson, H.C., Caraccio, T.R., Nawaz, H., Steckler, G., (1991). Acetaminopheninduced pancreatitis. Clin Toxicol, 29(2), 223-230. [DOI]

Musa, H., Sule, Y.Z., Gwarzo, M.S., (2011). Assessment of physicochemical properties of metronidazole tablets marketed in Zaria, Nigeria. Int J Pharm Pharm Sci, 3(3), 27-29.

Pabla, D., Akhlaghi, F., Zia, H., (2009). A comparative pH-dissolution profile study of selected commercial levothy-roxine products using inductively coupled plasma mass spectrometry. Eur. J. Pharm. Biopharm, 72(1), 105-110. [DOI]

Perneger, T.V., Whelton, P.K., Klag, M.J., (1994). Risk of kidney failure associated with use of acetaminophen, aspirin, and nonsteroidal antiinflammatory drugs. N Engl J Med, 331(25), 1675-1679. [DOI]

Prescott, L.F., Proudfoot, A.T., Cregeen, R.J., (1982). Paracetamol-induced acute renal failure in the absence of fulminant liver damage. Br Med J, 284(6313), 421422. [DOI]

Télez, M., Martínez, B., Criado, B., Lostao, C.M., Penagarikano, O., Ortega, B., Flores, P., Ortiz-Lastra, E., Alonso, R.M., Jiménez, R.M., Arrieta, I., (2000). In vitro and in vivo evaluation of the antihypertensive drug atenolol in cultured human lymphocytes: effects of long-term therapy. Mutagenesis, 15(3), 195-202. [DOI]

Vidhya Malar, H.L., Mary Mettilda Bai, S., (2012). Beware of Paracetamol Toxicity. J Clinic Toxicol, 2, 142. [DOI] 